\title{
On Analysis of Front End Current of Rectifier Converter for low THD and high PF with SEPIC
}

\author{
MIEEE Muhammad \\ EEE Department \\ Islamic University of Technology \\ Boardbazar, Gazipur-1704 \\ Bangladesh.
}

\author{
Md. Ashraful Hoque \\ EEE Department \\ Islamic University of Technology \\ Boardbazar, Gazipur-1704 \\ Bangladesh.
}

\begin{abstract}
Most of the power electronic equipments are operated with dc supply. For reliable and stable operation, dc supply should be regulated. The regulation can be performed using buck, boost, Cûk, Sepic, Flyback regulators. Except single phase rectifier with resistive load all other rectifiers input currents are non sinusoidal in nature. This front end current distortion of rectifier converter leads to low power factor, high THD, distribution system losses, neutral harmonic currents, over rated power equipments in a power system. Researchers have developed methods to reduce above mentioned problem. But large size and bulky filter are their drawbacks. Generally, boost converter topology is used at the output to overcome the limitation of three phase diode bridge rectifiers. But this arrangement provides only greater output voltage than input voltage. Few other topology like buck-boost, Cûk, flyback converters have been proposed to offer step up or down capability to meet the requirement. Not many studies have been reported in literature to make input current waveshaping of the rectifier converter using SEPIC. The aim of this research is to develop a Sepic regulator with improved input current quality for low THD and good power factor to ensure better efficiency for the system. In this work, a detailed study has been carried out to investigate the effect of ac to $\mathrm{dc}$ converter on input current that eventually injects harmonics into the power system. Various topologies of the converter with input and output passive filter arrangements have been investigated and it has been found that passive filters no longer provide optimal THD, input power factor and efficiency. Finally, a single ended primary inductor converter (SEPIC) has been proposed. The performance of the SEPIC with and without passive filter has been investigated through ORCAD simulation. It is seen that SEPIC with input passive filter provides best performances in terms of THD, input power factor and efficiency for the rectifier arrangement.
\end{abstract}

\section{General Terms}

Rectifier Converter, Simulation, Harmonic Analysis.

\section{Keywords}

Power Factor Correction, THD, ORCAD, SEPIC.

\section{INTRODUCTION}

Power electronics is playing a key role in various applications which include switch mode power supplies in computers and consumer electronics. Converters (i.e. rectifiers, inverters, and cyclo-converters etc) are used in adjustable speed drives, power supplies and UPS systems. Power systems are designed to operate at frequencies of $50 \mathrm{or} 60 \mathrm{~Hz}$. However, non linear types of loads produce currents with frequencies that are integer multiples of the 50 or $60 \mathrm{~Hz}$ fundamental frequency. These higher frequencies are a form of electrical pollution known as power system harmonics. Power factor correction (PFC) technique has been becoming a very important issue, since line harmonic current limitations will soon be set for the off-line equipment to protect the utility quality. Even nowadays, there are already some recommended limitations, like IEC 555-2, about the total harmonic distortion (THD) of the current drawn by the off-line equipment [1].

In recent years, three phase switch-mode AC/DC power converters shown in Fig 1. have been increasingly used in the industrial, commercial, residential, and aerospace environment

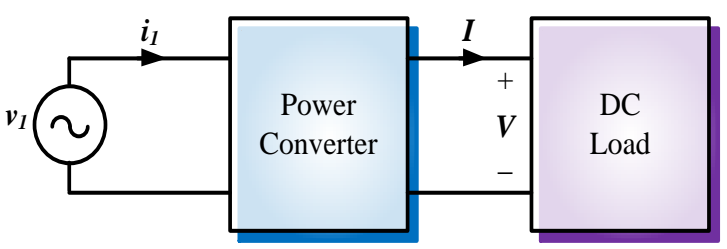

Fig 1: An ac-dc conversion system which transforms the ac line voltage $v 1$ into a dc voltage $V$ and current $I$ suitable for the dc load.

due to advantages of high efficiency, smaller size and weight. However, the proliferation of the power converters draw pulsating input current from the utility line, this not only reduces the input power factor of the converters but also injects a significant amount of harmonic current into the utility line. There are harmonic norms such as IEC 1000-3-2 introduced for improving power quality. By the introduction of harmonic norms now power supply manufacturers have to follow these norms strictly for the remedy of signal interference problem. The various methods of power factor correction can be classified as:

(1) Power factor correction using passive techniques

(2) Power factor correction using active techniques

In passive power factor correction techniques, an LC filter is inserted between the $\mathrm{AC}$ mains line and the input port of the diode rectifier of AC/DC converter. This technique is simple and rugged but it has bulky size and heavy weight and the power 
factor cannot be very high. Basically it is applicable for power rating of lower than $25 \mathrm{~W}$. For higher power rating it will be bulky. In active power factor correction techniques approach, switched mode power supply (SMPS) technique is used to shape the input current in phase with the input voltage. Thus, the power factor can reach up to unity. However, the complexity and relatively higher cost are the main drawbacks of this approach.

International regulations governing the power quality and harmonic currents pollution of the utility placed an increased emphasis on the problem of interfacing electronic dc loads to the utility line via power circuits. Such power circuit is called ac-dc converter and the conventional technique of doing this is to use the bridge rectifier with capacitor-input filter followed by a postregulator (dc-dc converter). The bridge rectifier converts ac voltage to dc while the capacitor forces the dc voltage to have small ripple. The post-regulator provides a regulated dc voltage to the load. The main problem associated with capacitor input filter are narrow-pulse, high peak currents which produce high harmonic currents on the utility line. These large harmonic currents are undesirable because they produce distortion of the line current. Only the components of input current which are of the same frequency and in phase with input voltage deliver active power to the load [2]. For ideal, sine-wave line voltage higher order harmonic currents do not contribute to load power but only generate the increased rms currents in the transmission lines and therefore, produce additional losses, degrade efficiency of the system.

The price of the extensive use of power electronic devices is becoming clear: increasing harmonic distortion. Since there is no viable alternative for these non-linear devices in electrical engineering, the subject of supply harmonics presently has broad interest. In order to limit the harmonic content of the line current of mains-connected equipment, there are different regulations in Europe (IEC 61000-3-2 Ed. 2.0:2000) [3] and America (IEEE 519). The European standard defines four different classes [4] for power electronic equipment. These classes establish different current harmonic limits depending on the use of the electronic equipment. In recent years, much effort has gone into finding cost-effective solutions in order to comply with these standards [5]-[6]. As passive solutions have some advantages such as lower cost, simplicity, roughness and absence of EMI, many researchers have intensified their efforts towards that method [7]-[11]. Also there are different topologies for implementing active power factor correction techniques. Comparing with the passive PFC techniques, active PFC techniques have many advantages such as, high power factor, reduced harmonics, smaller size and light-weight.

\section{RECTIFIER CONVERTER CONFIGURATION}

Industrial and commercial applications like adjustable drives, chemical process plant etc where three phase ac voltage are available from a few $\mathrm{KW}$ up to multi megawatt power level. Besides this, every year millions and millions of computer, LCD monitors and televisions are produced. With such a growing number of these devices actions must be taken to ensure the functionality of the power grid. It is preferable to use three phase rectifier circuit interface with the utility, compared to single phase rectifiers because of their lower ripple content in the waveforms and a higher power handling capability. There are two types of rectifiers namely uncontrolled diode rectifier and controlled thyristor rectifier for ac to dc conversion. Since these rectifiers draw non-sinusoidal currents, the power quality of the distribution network is greatly deteriorated, resulting in low

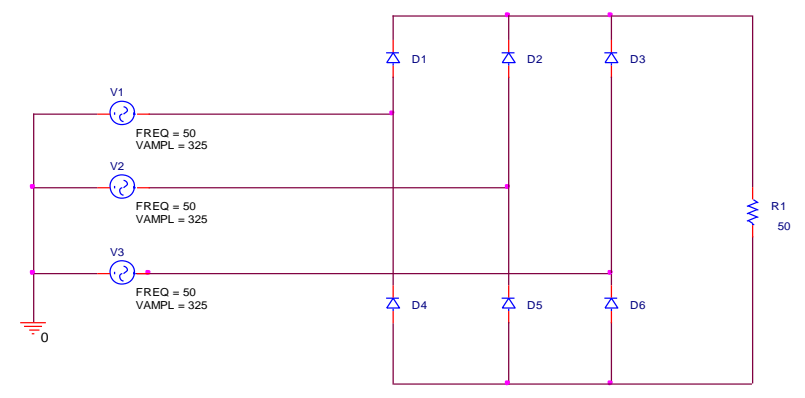

Fig 2: Schematic diagram of rectifier with resistive load

efficiency of utilities. The power factor of a three phase rectifier with resistive load remains close to unity. But with reactive load the power factor becomes lower. It is possible to improve input current to sinusoidal and power factor to unity by applying various control strategy. Here a diode bridge three phase rectifier is discussed with resistive load because of its simplicity.

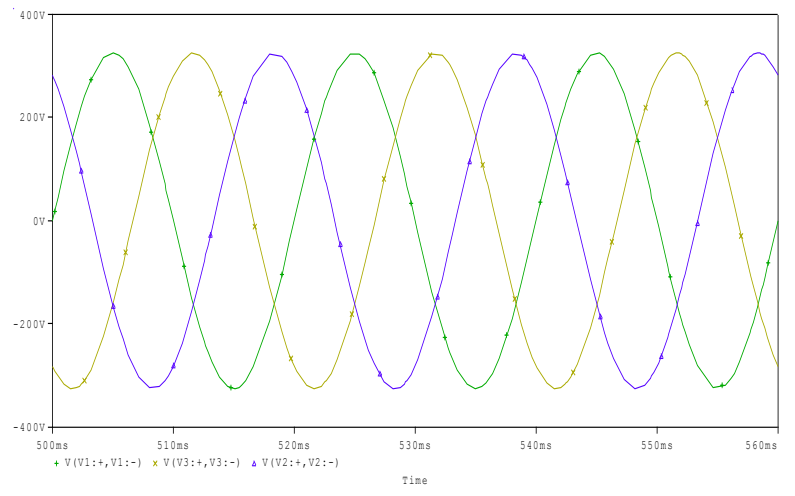

Fig 3: Input voltage of three phase rectifier

Three phase six diode full wave rectifier (FWR) is fed from star connected AC utility is shown in Fig 2. Each phase is apart by $120^{\circ}$ from each other having constant frequency. If $\mathrm{V}_{\mathrm{m}}$ is the peak value of the phase voltage, then the instantaneous voltages can be described by equation (1), (2) and (3) respectively.

$$
\begin{aligned}
\mathrm{V}_{\mathrm{an}} & =\mathrm{V}_{\mathrm{m}} \sin (\omega \mathrm{t}) \ldots \ldots \ldots \ldots \ldots \\
\mathrm{V}_{\mathrm{bn}} & =\mathrm{V}_{\mathrm{m}} \sin \left(\omega \mathrm{t}-120^{\circ}\right) \ldots \\
\mathrm{V}_{\mathrm{cn}} & =\mathrm{V}_{\mathrm{m}} \sin \left(\omega \mathrm{t}-240^{\circ}\right) \ldots
\end{aligned}
$$

The input voltage wave form in the circuit is shown in Fig 3. The diode of each phase conducts in $\mathrm{D}_{1} \mathrm{D}_{6}, \mathrm{D}_{2} \mathrm{D}_{6}, \mathrm{D}_{2} \mathrm{D}_{4}, \mathrm{D}_{3} \mathrm{D}_{4}$, $\mathrm{D}_{3} \mathrm{D}_{5}$ and $\mathrm{D}_{1} \mathrm{D}_{5}$ sequences through highest positive line to line voltage. The input current waveforms in the circuit of phase $a, b$ and $\mathrm{c}$ are shown in Fig 4. 


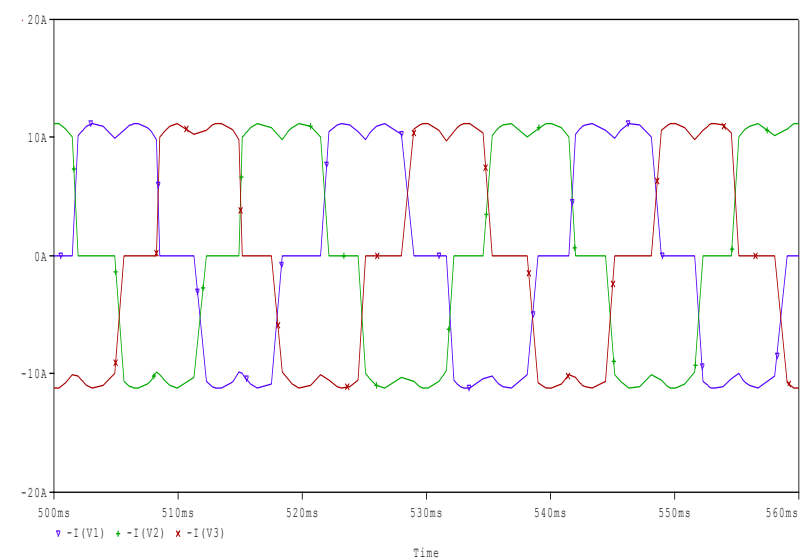

Fig 4: Input current of converter configuration

Consider the first period of each phase. Diode $D_{1}$ and $D_{2}$ conducts with highest positive voltage in phase $a$ and $b$, diode $\mathrm{D}_{6}$ conducts with highest negative voltage in phase $\mathrm{c}$. Then $\mathrm{D}_{2^{-}}$ $D_{6}$ and $D_{1}-D_{6}$ makes close path and allows to flow of current from phase $b$ to $c$ and a to $c$ through load. Diode $D_{1}$ and $D_{3}$ conducts with highest positive voltage in phase a and $\mathrm{c}$, at the same time diode $\mathrm{D}_{5}$ conducts with highest negative voltage in phase $b$. The $D_{1}-D_{5}$ and $D_{3}-D_{5}$ makes close path and allows to flow of current from phase $\mathrm{a}$ to $\mathrm{b}$ and $\mathrm{c}$ to $\mathrm{b}$ through load.

Similarly, the current flows from phase $\mathrm{c}$ to $\mathrm{b}$ and then from $\mathrm{c}$ to $a$, and at last the current flows from phase $b$ to $a$ and $b$ to $c$. Is is seen that, in every cycle diode $\mathrm{D}_{1}, \mathrm{D}_{2}, \mathrm{D}_{3}$ conducts positively for $120^{\circ}$ and $\mathrm{D}_{4}, \mathrm{D}_{5}, \mathrm{D}_{6}$ conducts negatively for $120^{\circ}$.

\section{CAPACITOR RECTIFIER ARRANGEMENT}

AC-DC converter comprises of a full-bridge rectifier followed by a large filter capacitor. The capacitor filter is usually a problem rather than a solution. The input current of such a rectifier circuit comprises of large discontinuous peak current pulses that result in high input current harmonic distortion. The high distortion of the input current occurs due to the fact that the diode rectifiers conduct only for a short period.

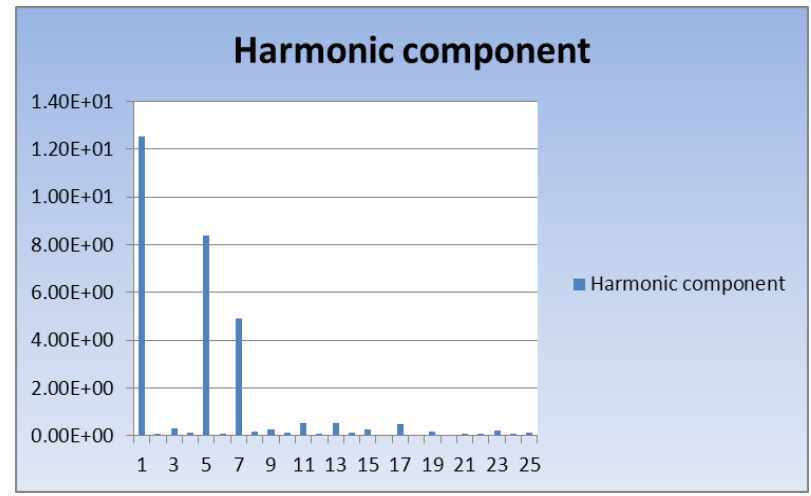

Fig 5: Frequency spectrum of current with capacitor

This period corresponds to the time when the mains instantaneous voltage is greater than the capacitor voltage.
Since the instantaneous mains voltage is greater than the capacitor voltage only for very short periods of time, when the capacitor is fully charged, large current pulses are drawn from the line during this short period of time. In the past, the use of this filter was justified in devices since the number of such devices was not so large. But in recent year, owing to the proliferation of the filters, net effect of having many of this low power devices operating on the same power line simultaneously is significant.

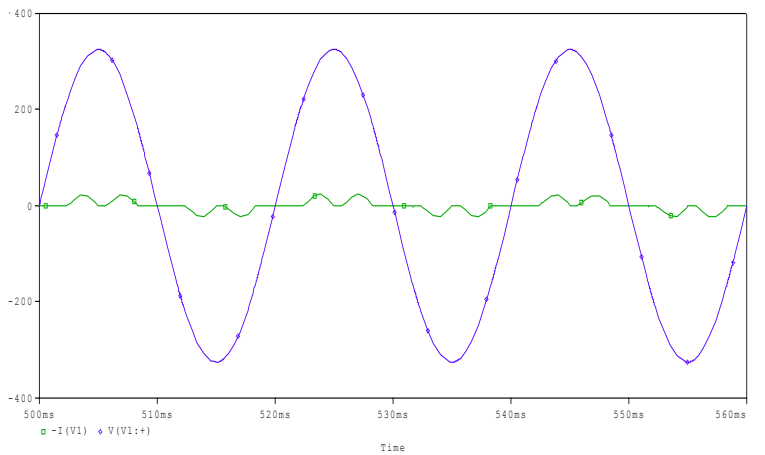

Fig 6: Phase relation of input voltage with input current

Power factor, THD, distortion and displacement factor are calculated for the three phase rectifier with output capacitor of value $100 \mathrm{uF}$. The discontinuous behavior of front end current for the capacitor filter contains total harmonic distortion as $78 \%$ which is very high and it needs to be reduced.

\section{PROPOSED PULSE WIDTH MODULATED SEPIC}

Sepic converter is proposed in this work which is shown in Fig 7. It becomes popular in recent years in battery-powered systems that have step up or down facility depending upon the charge level of the battery which overcomes the limitation of the conventional boost topology.

Cûk regulator which provides a negative polarity regulated output voltage with respect to the common terminal of the input voltage. A flyback converter (isolated buck-boost) requires a transformer instead of just an inductor, adding to the complexity of the development with the leakage inductance drop. Sepic regulator outperforms the above limitation.

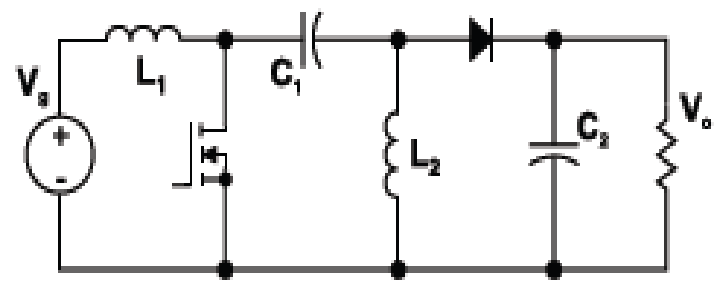

Fig 7: Sepic maintaining the same polarity reference for the input and the output 


\subsection{Operation Modes of SEPIC}

Mode 1: At turned on condition for the power switch, first inductor $\mathrm{L}_{1}$ is charged from the input voltage source during this time. The second inductor takes energy from the first capacitor. Output capacitor is left to provide the load current. In fact both $\mathrm{L}_{1}$ and $\mathrm{L}_{2}$ are disconnected from the load and provide isolation when the switch is on, as shown in Fig 8.

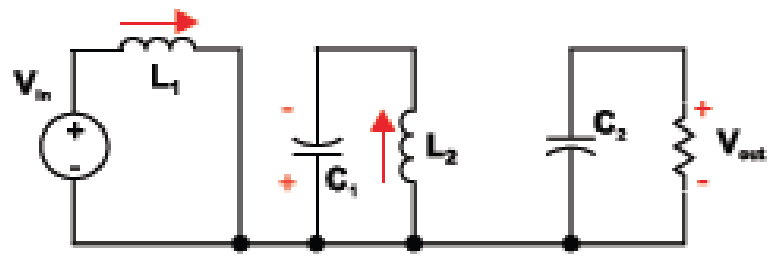

Fig 8: Power switch turned on condition, no energy is supplied to the load capacitor

Mode 2: At the time of turned off for the power switch, first inductor charges $C_{1}$ capacitor and also provides current to the load, as shown in Fig 9. The second inductor is also connected to the load during this time.

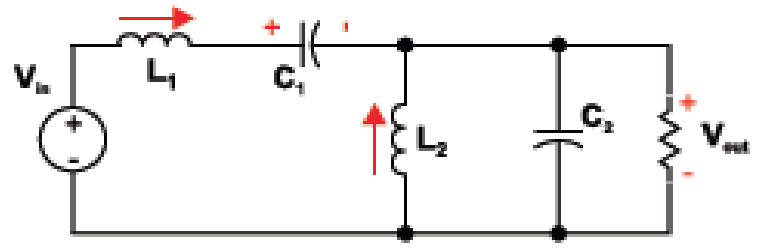

Fig 9: When the switch off, both inductors provide current to the load capacitor

$\mathrm{C}_{1}$ capacitor is moved from top to the bottom branch of the converter and inductor $\mathrm{L}_{2}$ is pulled over to the left, keeping its ends connected to the same nodes of the circuit. We replace the inductors with short circuit, and the capacitors with open circuit for the DC analysis of the switch model.

After some manipulation the KVL equation around the outer loop of the converter can be written as:

$$
\mathrm{V}_{\mathrm{g}}+\mathrm{V}_{\mathrm{o}}-\frac{1}{\mathrm{D}} \mathrm{V}_{\mathrm{o}}=0
$$

After rearranging, we can write:

$$
\mathrm{V}_{\mathrm{g}}=\left(\frac{1}{\mathrm{D}}-1\right) \mathrm{V}_{\mathrm{o}}=\frac{\mathrm{D}^{\prime \prime}}{\mathrm{D}}
$$

Gain of Sepic is given by:

$$
\mathrm{V}_{\mathrm{o}}=\frac{\mathrm{D}}{\mathrm{D}} \mathrm{Vg}
$$

The output is not inverted in SEPIC like the buck-boost and Cûk converters.

\section{RESULTS AND DISCUSSIONS}

Schematic diagram for pulse width modulated SEPIC with input filter is shown in Fig 13. To reduce the effect of switching harmonic, filter combination of $\mathrm{L}=20 \mathrm{mH}$ and $\mathrm{C}=50 \mathrm{uF}$ is used at the input side.

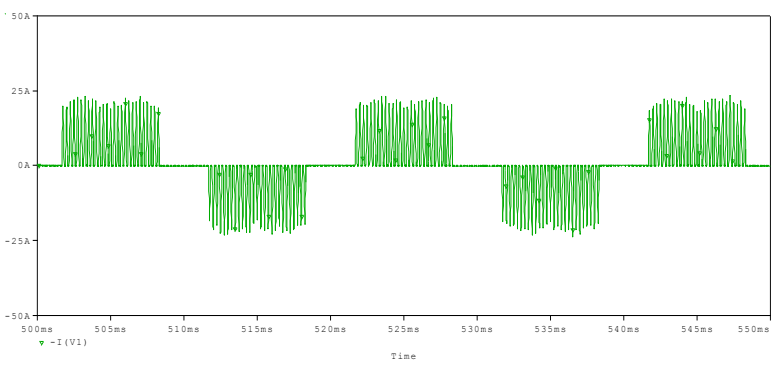

Fig 10: Input current for PWM SEPIC without filter

Power factor and total harmonic distortion of various power factor correction arrangements is shown in Fig 11. In the analysis it is seen that combined LC filter provides power factor of 0.5 only compared to 0.78 of the capacitive filter. Whereas only output filter provides power factor as 0.96 which is much better response in the PF

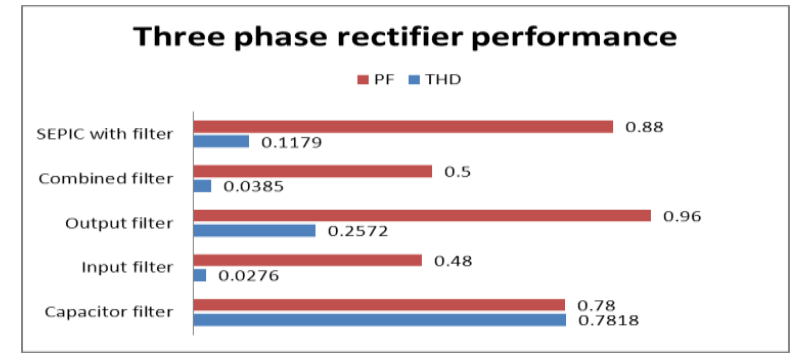

Fig 11: THD and power factor of various PFC

performance but it suffers from total harmonic problem. Thus we need to utilize input filter arrangement to overcome the limitation. The characteristic for the method provides small total harmonic distortion of 0.0276 while the power factor is only 0.48 which needs the improvement, as it is the worst condition among them.

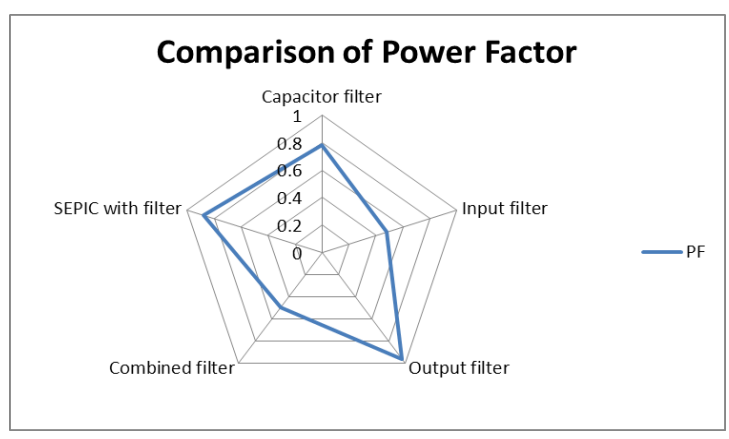

Fig 12: Power factor of various methods of PFC 
Power factor improvement characteristic is shown in Fig 12. Input filter arrangement has only about $50 \%$ power factor while SEPIC with input filter gives $88 \%$.

Table 1. Fourier analysis of transient response of input current for the proposed model with input filter

\begin{tabular}{|c|c|c|c|}
\hline HARMONIC & FOURIER & NORMALIZED & PHASE \\
\hline $\mathrm{NO}$ & COMPONENT & COMPONENT & (DEG) \\
\hline 1 & $1.292 \mathrm{E}+01$ & $1.00 \mathrm{E}+00$ & $-1.53 \mathrm{E}+02$ \\
\hline 2 & $4.38 \mathrm{E}-01$ & $3.36 \mathrm{E}-02$ & $4.71 \mathrm{E}+01$ \\
\hline 3 & $4.38 \mathrm{E}-01$ & $3.36 \mathrm{E}-02$ & $-8.54 \mathrm{E}+01$ \\
\hline 4 & $6.74 \mathrm{E}-01$ & $5.18 \mathrm{E}-02$ & $-3.25 \mathrm{E}+01$ \\
\hline 5 & $1.40 \mathrm{E}+00$ & $1.07 \mathrm{E}-01$ & $-1.61 \mathrm{E}+02$ \\
\hline 6 & $2.04 \mathrm{E}-01$ & $1.57 \mathrm{E}-02$ & $-7.61 \mathrm{E}+01$ \\
\hline 7 & $2.09 \mathrm{E}-01$ & $1.60 \mathrm{E}-02$ & $1.67 \mathrm{E}+02$ \\
\hline 8 & $8.71 \mathrm{E}-02$ & $6.69 \mathrm{E}-03$ & $6.49 \mathrm{E}+00$ \\
\hline 9 & $4.17 \mathrm{E}-02$ & $3.20 \mathrm{E}-03$ & $-1.17 \mathrm{E}+02$ \\
\hline 10 & $3.97 \mathrm{E}-02$ & $3.05 \mathrm{E}-03$ & $-1.88 \mathrm{E}+01$ \\
\hline 11 & $1.23 \mathrm{E}-01$ & $9.42 \mathrm{E}-03$ & $-4.02 \mathrm{E}+00$ \\
\hline 12 & $3.37 \mathrm{E}-02$ & $2.59 \mathrm{E}-03$ & $-6.53 \mathrm{E}+01$ \\
\hline 13 & $6.91 \mathrm{E}-02$ & $5.31 \mathrm{E}-03$ & $-3.49 \mathrm{E}+01$ \\
\hline 14 & $2.30 \mathrm{E}-02$ & $1.77 \mathrm{E}-03$ & $-3.43 E+01$ \\
\hline 15 & $4.24 \mathrm{E}-02$ & $3.26 \mathrm{E}-03$ & $2.10 \mathrm{E}+01$ \\
\hline 16 & $2.53 \mathrm{E}-02$ & $1.95 \mathrm{E}-03$ & $1.83 \mathrm{E}+01$ \\
\hline 17 & $2.07 \mathrm{E}-02$ & $1.59 \mathrm{E}-03$ & $-1.59 \mathrm{E}+02$ \\
\hline 18 & $1.93 \mathrm{E}-02$ & $1.48 \mathrm{E}-03$ & $4.87 \mathrm{E}+00$ \\
\hline 19 & $2.21 \mathrm{E}-03$ & $1.70 \mathrm{E}-04$ & $-7.24 \mathrm{E}+01$ \\
\hline 20 & $1.66 \mathrm{E}-02$ & $1.28 \mathrm{E}-03$ & $-1.37 \mathrm{E}+01$ \\
\hline
\end{tabular}

\section{CONCLUSION}

With the growing number of power electronic equipment and integration of it in the power system leads to poor and lagging input power factor. It also introduces increase of total harmonic distortion (THD) of the front end current. As for example, the three phase rectifier that has been used in many applications distorts the input current thus input power factor is reduced and efficiency is poor. To counter balance the effect, line side passive filter is introduced which improves THD but the power factor is reduced for this structure due to input passive current filter arrangement. The arrangement of output passive filter has been used to remove the ripple content from output parameter, but it generates rectangular wave of the input current which contains higher total harmonic distortion. This problem of high THD has been solved with the expense of both input and output passive filter in the same combination. Although the configuration provides better response to the total harmonic distortion, but it has bulky structure which may affect the regulation. Also it is seen that the power factor is very low in this case.
To overcome all the above limitations (ie size for passive, greater output parameter for boost, negative polarity issue for cûk and transformer structure for flyback) the pulse width modulated SEPIC with input filter has been proposed in this work. It is observed that it handles the three phase diode rectifier configuration with an improved THD. Also it has small inductor requirement compared to other topologies to achieve the improved power factor. It has an added advantage of flexibility of the output that is lesser or greater than the input with the positive polarity in terms of same ground facility to control the load end dc block.

In this work, a detailed study has been carried out to investigate the effect of ac to dc converter on input current that eventually injects harmonic into the power system. Various topologies of the converter with input and output passive filter arrangements have been investigated and it has been found that passive filters no longer provide optimal THD, input power factor and efficiency. Finally, a single ended primary inductor converter (SEPIC) has been proposed. The performance of the SEPIC with and without passive filter has been investigated through ORCAD simulation. It is seen that SEPIC with input passive filter provides optimum performances in terms of THD as well as input power factor of the system.

\section{REFERENCES}

[1] Yanchao J. and Wang F., " Single-Phase Diode Rectifier with Novel Passive Filter", IEE Proc.-Circuits Devices Syst., Vol. 145, No. 4, August 1998, pp. 254-259.

[2] Brkovic M. and Cuk S., "Input Current Shaper using Cuk Converter”, 1992 IEEE, pp.532-539.

[3] Electromagnetic Compatibility (EMC) Part 3-2: Limits for Harmonic Current Emissions (Equipment Input Current 16 A Per Phase), IEC-61 000-3-2, 2000.

[4] Gandoy, J. D., Castro C., and Martínez M. C., "Line Input AC-to-DC Conversion and Filter Capacitor Design." IEEE Trans. Ind. Appl., VOL. 39, NO. 4, 2003, pp.1169-1176

[5] Lin W. M., Hernando M. M., Fernandez A., Sebastian J., and Villegas P. J., "Design of the Basic Rectifier with LC Filter to Comply with the New Edition of the IEC1000-3-2 Current Harmonic-Limit Specifications (Edition 2.0)," in Proc. IEEE PESC, 2002, pp. 1215-1220.

[6] Key T. S. \& Lai J. S., "Comparison of Standard and Power Supply Design Options for Limiting Harmonic Distortion", IEEE Trans. on Ind. Applications, Jul./Aug., 1993, pp.688695 .

[7] Redl R., "An economical single-phase passive power-factorcorrected rectifier: Topology, operation, extensions and design for compliance," in Proc. IEEE APEC'98, 1998, pp. $454-460$.

[8] Prasad, A.R., Ziogas, P.D., and Manlas, S.: 'A novel passive waveshaping method for single-phase diode rectifiers', IEEE Trans. Ind. Electron., 1990, VOL. 37, NO. 6, pp. 521 530. 
[9] Mohan, N., Undeland T. M., and Robbins W. P., Power Electronics, Converters, Applications, And Design, 2nd Edition, John Wiley and Son, Inc., New York, 1995.

[10] Freeland S. D., "Input current shaping for single phase acdc power converters" Ph.D thesis, California Institute of Technology.

[11] Jha A. K., Fernandes B. G. and Kishore A. "A Single Phase Single Stage AC/DC Converter with High Input Power Factor and Tight Output Voltage Regulation," Prog. In Electromagnetics Research Symp. 2006, Cambridge, USA, March 26-29

[12] Abedin A. H., Ahmed M. R., and Alam M. J. "Improvement of input side currents of a three phase rectifier combining active and passive filters," Journal of
Electrical Engineering, Vol. EE 33. No I \& II, December 2006

[13] Reza H.B.," Design of a high efficiency controlled rectifier by two stage cuk conversion" M.Sc. thesis , Bangladesh University of Engineering and Technology, December 2009

[14] Kazem H.A., "Input current waveshaping methods applied to single phase rectifier", in Proc. of International Conference on Electrical Machines and Systems 2007, Oct. 8-11, Seoul, Korea pp.54-57.

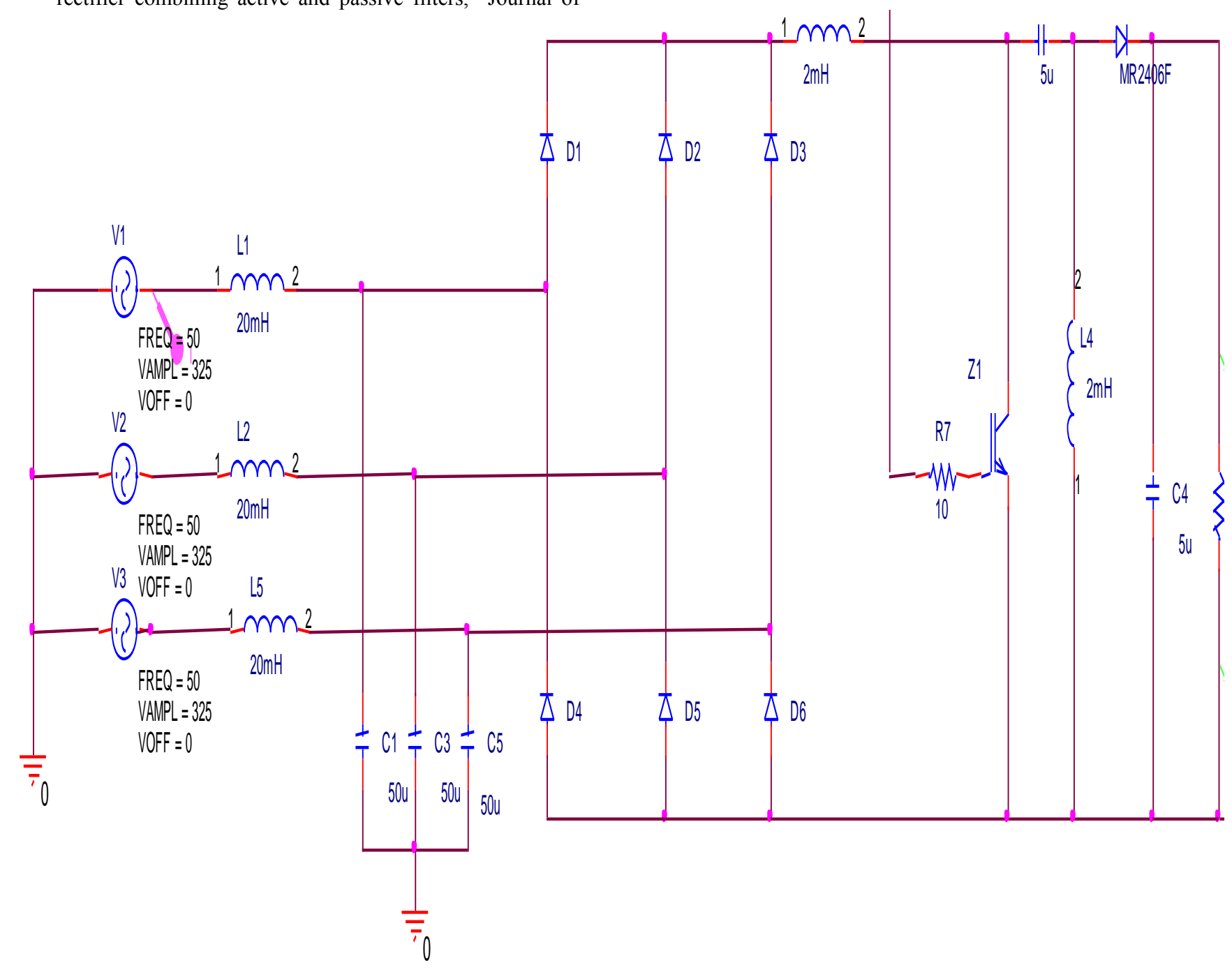

Fig 13: Three phase rectifier with proposed PWM Sepic and input filter 